\title{
СТРАТЕГИЧЕСКАЯ АДАПТАЦИЯ ГЛОБАЛЬНЫХ ЭНЕРГЕТИЧЕСКИХ КОМПАНИЙ В КОНТЕКСТЕ ТРЕНДА НА НИЗКОУГЛЕРОДНУЮ ЭКОНОМИКУ
}

\section{STRATEGIC ADAPTATION OF GLOBAL ENERGY COMPANIES IN THE CONTEXT OF THE TREND TOWARDS A LOW-CARBON ECONOMY}

O. Orlova

Summary. In the context of the climate agenda actively promoted by the international community and the increasing pressure from all stakeholders, global energy companies cannot stay away from the process of decarbonization of the world economy. Otherwise, they risk not only losing a significant market share, but also facing a dramatic drop in demand, which can lead to unsolvable financial problems. In this regard, the issues of adaptation of the development strategy become a priority task of corporate governance and top management of key players in the energy market.

Keywords: decarbonization, climate risks, carbon footprint, risk management, risk identification.

\author{
Орлова Ольга Юрьевна \\ Доктор экономических наук, профессор \\ Санкт-Петербургский государственный \\ экономический университет \\ oorlova@mail.ru
}

Аннотация. В условиях активно продвигаемой международным сообществом климатической повестки и усиливающимся давлением всех заинтересованных сторон, глобальные энергетические компании не могут оставаться в стороне от процесса декарбонизации мировой экономики. В противном случае они рискуют не только потерять существенную долю рынка, но и столкнуться с драматическим падением спроса, которое может привести к неразрешимым финансовым проблемам. В связи с этим, вопросы адаптации стратегии развития становятся приоритетной задачей корпоративного управления и топ менеджмента ключевых игроков энергетического рынка.

Ключевые слова: декарбонизация, климатические риски, углеродный след, риск менеджмент, идентификация рисков.
B настоящий момент можно констатировать что тренд на низкоуглеводное развитие прочно занял ведущие позиции в международной экономической повестке, определив необходимость адаптации корпоративного сектора в области как стратегических целей, как и текущих бизнес-задач. Проеденное исследование лучших корпоративных практик глобальных энергетических компаний позволило выделить основные направления в трансформационных процессах экономических агентов, вызванных активной климатической риторикой.

Методической основной исследования выступил комплексный анализ климатических стратегий и предполагаемых мероприятий, направленных на снижение вредного воздействия на окружающую среду глобальных энергетических мейджоров, крупнейших энергетических компаний, а также крупнейшие российские компании и компании - лидеры глобальной и российской климатической повестки.

В результате проведенного исследования были определены следующие ключевые элементы стратегий адаптации компаний к глобальной тенденции декарбонизации всех отраслей мировой экономики:

1. В заявленных стратегиях большинства анализируемых компаний содержится количественная оценка углеродного следа, при этом следует отметить, что основные мейджоры энергетического рынка, такие как BP, Chevron, Equinor, ENI, ENEL в обязательном порядке раскрывают в своей публичной отчётности количественные углеродные метрики в разрезе SCOP 1,2,3, в отличие от российских компаний, в отчетности которых данная информация по большей части не отражается.

2. Глобальные энергетические компании, освещая стратегические направления развития бизнеса рассматривают потенциальные угрозы с учетом климатических рисков в двух основных аспектах: физические риски и риски переходного периода. При этом основное внимание в стратегии таких компаний как: Chevron, ENEL, ConocoPhillips, Equinor, Petrobras, EN+, ENGIE, EQT уделяется рискам переходного периода, среди которых особо отмечаются следующие группы рисков: 
Таблица 1. Отражение углеродных метрик в публичной отчетности компаний.

\begin{tabular}{|c|c|c|c|}
\hline Наименование компании & $\begin{array}{l}\text { Целевые показатели } \\
\text { по выбросам СО2 }\end{array}$ & $\begin{array}{l}\text { Целевые показатели } \\
\text { выбросов } \\
\text { в разрезе } \\
\text { SCOP } 1,2,3\end{array}$ & $\begin{array}{l}\text { Отслеживается динамика } \\
\text { показателей выбросов } \\
\text { СО2 }\end{array}$ \\
\hline $\begin{array}{l}\text { BP, Chevron, ENEL, ENI, ConocoPhillips, Equinor, } \\
\text { Petrobras, Royal Dutch Shell Repsol, TotalEnergies, } \\
\text { Uniper, ExxonMobil, CNOOC }\end{array}$ & + & + & + \\
\hline $\begin{array}{l}\text { EN+, ENGIE, EQT, Corp PEMEX, Phillips, Saudi Aramco } \\
\text { Sinopec Southwestern Energy }\end{array}$ & - & - & - \\
\hline $\begin{array}{l}\text { АО «Архангельский ЦБК», ПАО «Новатэк», ПАО } \\
\text { «Ттнефть», ПАО «ФосАгро» }\end{array}$ & + & + & + \\
\hline $\begin{array}{l}\text { АО «Полиметалл», ГК «Росатом», ПАО «АФК } \\
\text { Система», ПАО «Интер РАО», ПАО «РОСнефть», ПАО } \\
\text { «Сургутнефтегаз», ПАО «СУЭК», ООО «Газпром } \\
\text { энергохолдинг», ПАО «Газпром нефть» }\end{array}$ & + & - & + \\
\hline
\end{tabular}

Составлено автором на основе информации годовых отчетов компаний и отчетов по устойчивому развитию за 2019-2020 гг.

- Регуляторной риск - риск изменения законодательства, введение углеродного налога, дополнительных требования и ограничений для компаний с высоким углеродным следом

- Рыночный риск - снижение спроса на конечную продукцию компании обусловленный процессами декарбонизации и изменением потребительской корзины за счет увеличения доли энергии из возобновляемых источников

- Операционный риск - рост операционных затрат вследствие изменения стоимости и доступности финансовых ресурсов, удорожания технологических процессов при внедрении технологий нейтрализации вредного воздействия промышленных процессов на окружающую среду, рост налоговой нагрузки.

- Репутационные риск - возникновение негативного информационного фона в связи с формированием в социальном пространстве этического отказа от потребления продукции с существенным углеродным следом, общественного порицания в отношении компаний, наносящихся существенный вред окружающей среде, развитие судебной практики в части исковых заявлений к компаниям, которые не декларируют приверженность политике борьбы с изменениями климата.

Вторая группа международных энергетических компаний из исследуемой выборки (BP, ENI, Petrobras, Royal Dutch Shell Repsol, TotalEnergies, Uniper, ExxonMobil, CNOOC, Corp PEMEX, Phillips, Saudi Aramco, Sinopec Southwestern Energy) не проводит детализированную идентификацию климатических рисков, выделяя лишь совокупный климатический риск, основная угроза ко- торого состоит в падении совокупного мирового спроса на природные углеводороды и негативной ценовой динамике. Следует отметить, что отдельные компании такие как: Chesapeake Energy, Valero Energy, Uniper, трактуют климатический риск как необходимую составляющую в общей совокупности ESG рисков, рассматривая проблему климатического риск-менеджмента в более широком контексте возрастающего влияния экологических, социальных факторов и качества корпоративного управления на способность компании демонстрировать уверенность в достижении заявленных стратегических целей, в том числе в области климатических метрик.

Можно заключить, что в качестве основных вызовов сформировавшегося тренда на декарбонизацию мировой экономики глобальные энергетические компании видят сжатие спроса на природные углеводороды и рост стоимости производства (добычи) и транспортировки вследствие введения нового правого регулирования, направленного на стимулирование углеродонейтрального потребления и снижение углеродоёмкости промышленного производства.

Исследуемая группа российских компаний в части идентификации климатических рисков, следует лучшим международным корпоративным практикам, детально отражая всю совокупность переходных климатических рисков, также выделяя при этом четыре основные группы: регуляторный, рыночный, операционный и репутационный риски. Ряд российских компаний (ПАО «Лукойл» ПАО, «Газпром нефть») к рискам перехода также относит технологические риски, которые определяют как риск потери определенной доли рынка, связанного с активным развитием инновационных технологий в области альтернативной энергетики. 
3. Российские компании, в отличии от западных коллег, в процессе идентификации климатических рисков, выделяют не только большую группу переходных рисков, но и довольно серьезное внимание уделяют физическим рискам, связанным с глобальным изменением климата, например таянию вечной мерзлоты, возрастающей вероятности стихийных бедствий (наводнений), которые могут нанести существенный урон действующим производственным и транспортным мощностям. Группа отечественных компаний, включающих ПАО «ФосАгро», ПАО «Роснефть», ГК «Росатом» особо выделяет следующие группы физических рисков:

- Риски физического воздействия последствий изменения климата - нарушение технологических процессов производства и логистических операций вследствие усиливающихся острых климатических воздействий, нанесение ущерба в процессе проектирования и строительства промышленной инфраструктуры под воздействием краткосрочных негативных погодных явлений, вызванных глобальным изменение климата;

- Экологические риски - риск негативного воздействия на окружающую среду вследствие нарушения производственного цикла и промышленной безопасности в результате резких климатических изменений.

3. Исследование показало, что терминологический аппарат, используемый компаниями для идентификации и определения основных групп климатических рисков, оказывает существенное влияние на формирование климатической политики в части определения ключевых метрик и инструментария при формировании стратегического видения развития компании в контексте текущей климатической повестки. Основной всех заявленных стратегий являются цели по снижению выбросов СО2, мониторинг и контроль установленных углеродных метрик. Для достижения заявленных целей компании предусматривают следующее:

- Установление долгосрочных стратегических целей в области борьбы с изменением климата, основанных на количественной оценке выбросов CO2 и декларирование программы мероприятий, направленных на его снижение

- Внедрение углеродного менеджмента в систему корпоративного управления компании, в том числе на уровне Совета директоров, включение климатических метрик в систему материального стимулирования персонала

- Формирование внутренней цены на углерод которая выступает существенным фактором в процессе принятия управленческих и инвестиционных решений

- Публикационная активность компаний в части повышения доступности и прозрачности нефи- нансовой отчетности, формируемой в соответствии с международными стандартами (необходимо отметить, что ряд компаний при этом отказывается от публикаций в формате CDP в связи с низкой востребованностью среди основных стейкхолдеров)

- Поддержка и развитие научно-технического сотрудничества в области технологического обеспечения адаптации промышленного производства к политике углеродной нейтральности

- Изменение бизнес-модели компании в пользу увеличения доли продукции с низким углеродным следом

- Внедрение регулярного экологического мониторинга в операционные процессы корпоративного риск-менеджмента

Следует особо подчеркнуть, что приведенный перечень мероприятий является далеко не исчерпывающим. В связи с обострившейся климатической полемикой компании вынуждены постоянно актуализировать и пополнять список рисков, связанных с глобальным изменением климата. Как показало исследование, в условиях отсутствия единого терминологического и методологического подхода к идентификации и управлению климатическими рисками, корпоративные практики в этой области могут существенно различаться в зависимости от видения руководства компании, отраслевой и технологической специфики бизнеса, географии поставок и производственных цепочек. Подобная ситуация формирует информационные диспропорции, которые создают сложности в адекватной оценке стратегических перспектив компании заинтересованными сторонами, в том числе потенциальными инвесторами.

Вместе с тем, для всех компаний энергетического сектора характерно усложнение структуры выявляемых климатических рисков, реализация которых может привести к расширению перечня уязвимостей организации в контексте новой климатической реальности. Отмеченный тренд предъявляет повышенные требования к качеству корпоративного риск менеджмента - усложнение процедур идентификации рисков, выявление и детальное описание источников их возникновения, количественная и качественная оценка вероятного ущерба нуждаются в адекватной и эффективной корпоративной методике в части управления рисками, связанными с глобальным изменением климата. Постоянно расширяющийся и модифицирующийся перечень рисков, имеющих тесную взаимосвязь с климатической повесткой, влечет за собой потребность компании в таком же широком и разнообразном наборе мероприятий, направленных на их устранение или нейтрализацию их пагубного воздействия на инвестиционный потенциал и позицию компании на глобальном энергетическом рынке. 
ЛИТЕРАТУРА

1. Мотосова Е.А., Потравный И.М. Плюсы и минусы введения углеродного налога: зарубежный опыт и позиция России по Киотскому протоколу // ЭКО. 2014. № 7 (481). С. 180-189

2. Влияние климатических рисков и устойчивое развитие финансового сектора Российской Федерации. Доклад для общественных консультаций. Банк России — Москва, 2020. https://cbr.ru/Content/Document/File/108263/Consultation_Paper_200608.pdf

3. Корпоративные стратегии углеродной нейтральности. Обзор климатических обязательств мировых компаний. Министерство экономического развития.—-Москва, 2021, https://www.economy.gov.ru/material/file/f55d57f8dcbb8ec195b1575e857610dc/03062021.pdf

4. NGFS (Network of Central Banks and Supervisors for Greening the Financial System). 2019. A Call for Action: Climate Change as a Source of Financial Risk. Paris: NGFS Secretariat. https://www.ngfs. net/en/first-comprehensive-report-call-action

с С Орлова Ольга Юрьевна ( oorlova@mail.ru).

Журнал «Современная наука: актуальные проблемы теории и практики»

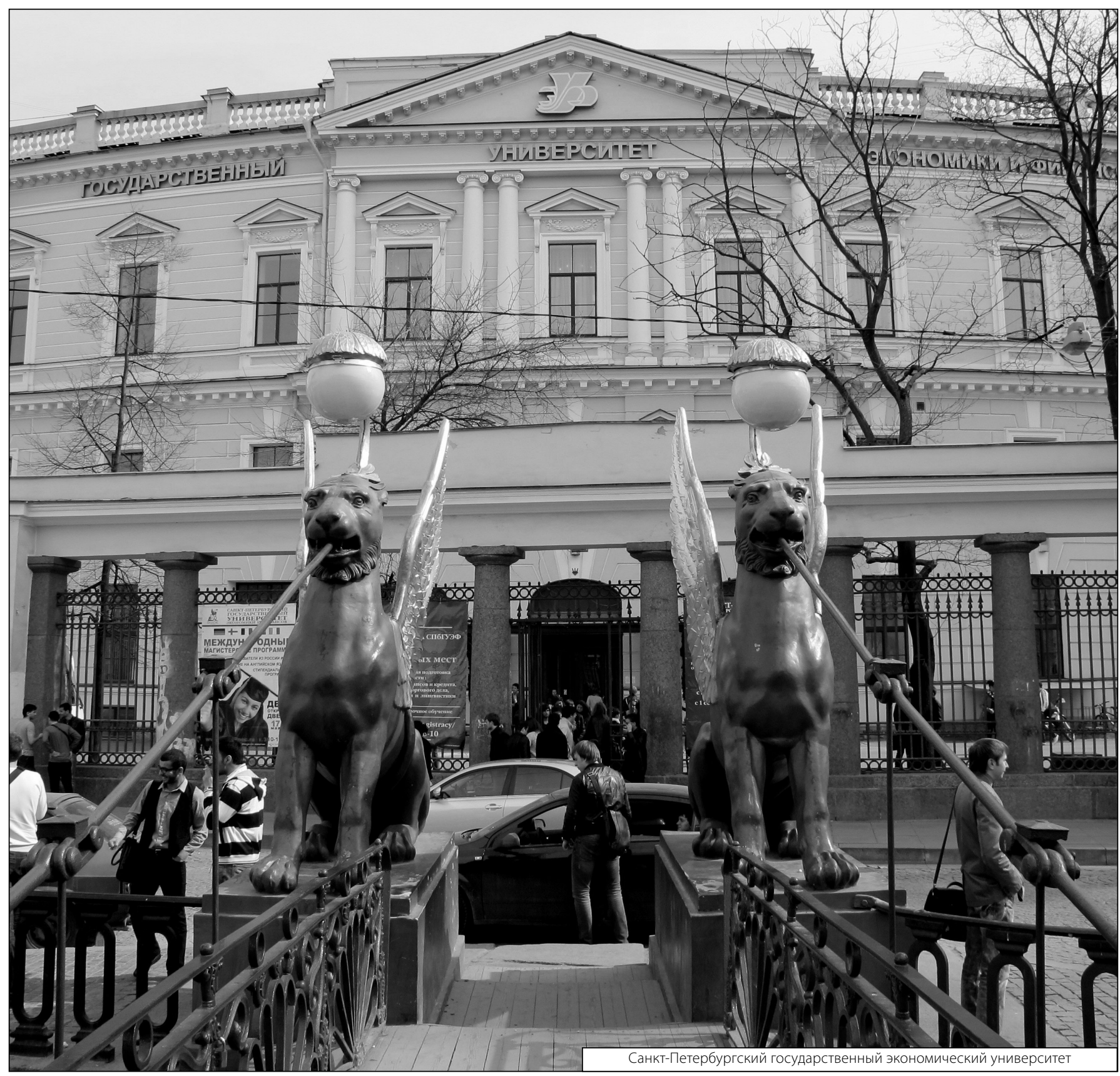

